\title{
Statistical and Physical Descriptions of Raindrop Size Distributions in Equatorial Malaysia from Disdrometer Observations
}

\author{
Hong Yin Lam, ${ }^{1}$ Jafri Din, ${ }^{1}$ and Siat Ling Jong ${ }^{1,2}$ \\ ${ }^{1}$ Department of Communication Engineering, Faculty of Electrical Engineering, UTM, 81310 Skudai, Johor, Malaysia \\ ${ }^{2}$ Department of Communication Engineering, Faculty of Electrical and Electronic Engineering, UTHM, \\ 86400 Batu Pahat, Johor, Malaysia \\ Correspondence should be addressed to Jafri Din; jafri@fke.utm.my
}

Received 1 July 2014; Accepted 19 September 2014

Academic Editor: Francisco J. Tapiador

Copyright ( 2015 Hong Yin Lam et al. This is an open access article distributed under the Creative Commons Attribution License, which permits unrestricted use, distribution, and reproduction in any medium, provided the original work is properly cited.

This work investigates the physical characteristics of raindrop size distribution (DSD) in an equatorial heavy rain region based on three years of disdrometer observations carried out at Universiti Teknologi Malaysia’s (UTM's) campus in Kuala Lumpur, Malaysia. The natural characteristics of DSD are deduced, and the statistical results are found to be in accordance with the findings obtained from others disdrometer measurements. Moreover, the parameters of the Gamma distribution and the normalized Gamma model are also derived by means of method of moment (MoM) and maximum likelihood estimation (MLE). Their performances are subsequently validated using the rain rate estimation accuracy: the normalized Gamma model with the MLE-generated shape parameter $\mu$ was found to provide better accuracy in terms of long-term rainfall rate statistics, which reflects the peculiarities of the local climatology in this heavy rain region. These results not only offer a better understanding of the microphysical nature of precipitation in this heavy rain region but also provide essential information that may be useful for the scientific community regarding remote sensing and radio propagation.

\section{Introduction}

Raindrop size distribution (DSD) has received much attention over the past few decades due to its shape of distribution, which reflects the fundamental microphysics of rain $[1,2]$. In fact, the knowledge of DSD not only plays an important role in the atmospheric science/meteorology communities [3], which describe the processes that transform condensed water into rain, but is also important for the remote sensing of precipitation and radio-link propagation performance. Rainfall measurement via ground-based weather radar or spaceborne satellite observation requires the characteristics of the raindrop spectra for the development of rainfall retrieval algorithms [4,5], while in satellite communication links, DSD is the dominant parameter that causes attenuation, which leads to significant performance degradation for frequencies above $10 \mathrm{GHz}[6,7]$.
To this end, in order to accurately estimate precipitation rate, much progress has been made in representing the natural variation of DSD. Starting with early ground measurement using the flour method [2] and filter paper [1], followed by impact-type disdrometer [8] and advanced 2DVD video disdrometer [9], a great deal of effort has been devoted to the modeling of DSD from the observation of real DSD. Initially, based on the experimental measurements, Law and Parson proposed an exponential distribution [2] to represent DSD:

$$
N(D)=N_{o} \exp (-\Lambda D),
$$

where $N$ is the number of drops per unit volume per unit interval of drop diameter $D, N_{o}$ is the intercept parameter, and $\Lambda$ is the slope parameter. Then, Marshall and Palmer [1] suggested a fixed value for $N_{o}$ of $8000 \mathrm{~m}^{-3} \mathrm{~mm}^{-1}$, while $\Lambda=$ $4.1 R^{0.21}$ can be deduced from the relationship with the rainfall 
rate $R$ in $\mathrm{mm} / \mathrm{h}$. Subsequently, the Gamma distribution has been introduced to better account for the shape of the distribution with respect to the high rainfall rate. The Gamma model can be written as [3].

$$
N(D)=N_{o} D^{\mu} \exp (-\Lambda D)
$$

where $\mu$ is the shape parameter (dimensionless). The three parameters $\left(N_{o}, \mu\right.$, and $\left.\Lambda\right)$ can be deduced from the measured DSD by means of the method of moments, which has been widely accepted in the meteorology community $[10,11]$. In addition to the above mentioned models, the modified Gamma [12] and the lognormal models [13] are also worth underlining as alternatives.

Nevertheless, based on the evidence from several DSD measurements carried out in various locations across different regions, it is generally accepted that DSD is best modeled via a Gamma distribution, as pointed out by Ulbrich [3]. Since then, extensive studies have been focused on identifying the best matching moments, such as 2nd, 3rd, 4th, (MM234), 4th, 5th, and 6th (MM456) or 3rd, 4th, and 6th (MM346), with which one can infer the Gamma distribution parameters. Due to the insensitivity of impact disdrometer in detecting smaller drop, most of the authors chose to employ central moments. Tokay and Short [10] and Kozu and Nakamura [11] used MM346 to model the Gamma DSD, while Timothy et al. [14] used the same moments to model lognormal DSD in the Singapore region. Other authors tend to use the MM234 [15] and MM246 [4] moments. Caracciolo et al. [16] prefer to work with higher-order moments, such as MM456, with the aim of reducing the dependency on small drops during heavy rain events. However, Smith and Kliche [17] highlighted the possibility of a strong bias with the use of higher-order moments. As a matter of fact, any of these moments can be used for DSD parameterization, and the choice usually depends on the desired rainfall parameter. For instance, higher-order moments should be used for the estimation of the rain rate $R$ and the radar reflectivity factor $Z$ because $R$ is proportional to the 3.67 th moment, whereas $Z$ is the 6 th moment of the drop spectrum. In addition, there are also some efforts focused on empirically relating any two of the Gamma parameters, with the aim of reducing the threeparameter function to a two-parameter function $[18,19]$.

In the past few years, the radar meteorology community and remote sensing researchers have tended to represent the DSD via a normalized model due to its clear physical representation of DSD parameters with respect to the Gamma model. The normalized concept was first introduced by Willis [20] and further adapted by Testud et al. and Illingworth and Blackman [21, 22] for the precipitation radar applications. As mentioned previously, the three Gamma parameters $\left(N_{o}\right.$, $\mu$, and $\Lambda$ ), are physically meaningless [21], and the concepts of the normalized model overcome such drawbacks by removing the dependence of $N_{o}-\Lambda$ and representing the DSD parameters with physically meaningful parameters, such as the total liquid water content and the mean drop size.

One relevant issue for DSD modeling is the variability of natural DSD, which depends on the interaction between kinematic, microphysical, and dynamic processes [3, 23].
This intrinsic variability may even be noted across different climatologically conditions and geographical areas [24]. For this reason, many field studies were carried out at various locations throughout the world to observe the peculiar characteristics of DSD via ground or aircraft measurement. These observations cover a variety of climatic regions, from mid-latitude [25, 26], maritime, continental [27], and tropical $[10,28-32]$ to equatorial environments $[33,34]$. In fact, findings from these studies are crucial for the modeling of DSD and the retrieval algorithms for remote sensing at different geographical areas. This is even more critical in the equatorial areas, where the precipitation mechanism exhibits localized features rather than regional features [35]. Indeed, additional findings or studies with respect to the natural DSD characteristics in equatorial areas should lead to a better understanding of DSD in these particular areas.

With the aim of improving the understanding of DSD in this extremely heavy rain area, this work presents the natural characteristics of DSD in equatorial Malaysia by exploiting three years of long-term measurements collected via disdrometer in Kuala Lumpur, Malaysia. In addition, the driving parameters of the Gamma and normalized Gamma models are also inferred from this dataset, and their statistical features are duly discussed, together with their empirical relationship. Eventually, the effectiveness of both models is evaluated through rainfall estimation.

The remainder of the paper is organized as follows. Section 2 describes the disdrometer measurement details. Afterwards, the unique characteristics of equatorial precipitation are briefly explained in Section 3. The core of the paper lies in Section 4, where the features of natural DSD in this area are first presented. In the same section, the statistical results of the DSD parameters from the Gamma and normalized Gamma models are demonstrated. The relationship between these parameters is subsequently derived from disdrometer observations and the performance of the Gamma and normalized Gamma models in estimating the rain rate for equatorial Malaysia is evaluated. Finally, a summary of the results and conclusions are given in Section 5.

\section{Measurement Details}

A Joss-Waldvogel disdrometer (JWD, RD-69) was installed on a roof of a $15 \mathrm{~m}$ building (at an altitude of $35 \mathrm{~m}$ above mean sea level) located on the Universiti Teknologi Malaysia (UTM) campus in Kuala Lumpur, Malaysia, situated at $3.08^{\circ} \mathrm{N}$ and $101.42^{\circ} \mathrm{E}$. The measurements were taken from January 1992 to December 1994; the disdrometer recorded about 100,512 rainy minutes with a 1-minute integration time, which represented $30,960 \mathrm{~mm}$ of rainfall over 781 rain events. Each event was identified using a clear sky duration of at least 60 minutes between one event and the following one. The measurement system of the RD-69 is illustrated in Figure 1.

The RD-69 disdrometer measurement system mainly consists of three units, namely, the disdrometer (transducer), which is located outdoors and is connected to the processor and the analog-to-digital converter (ADA-90), which are 


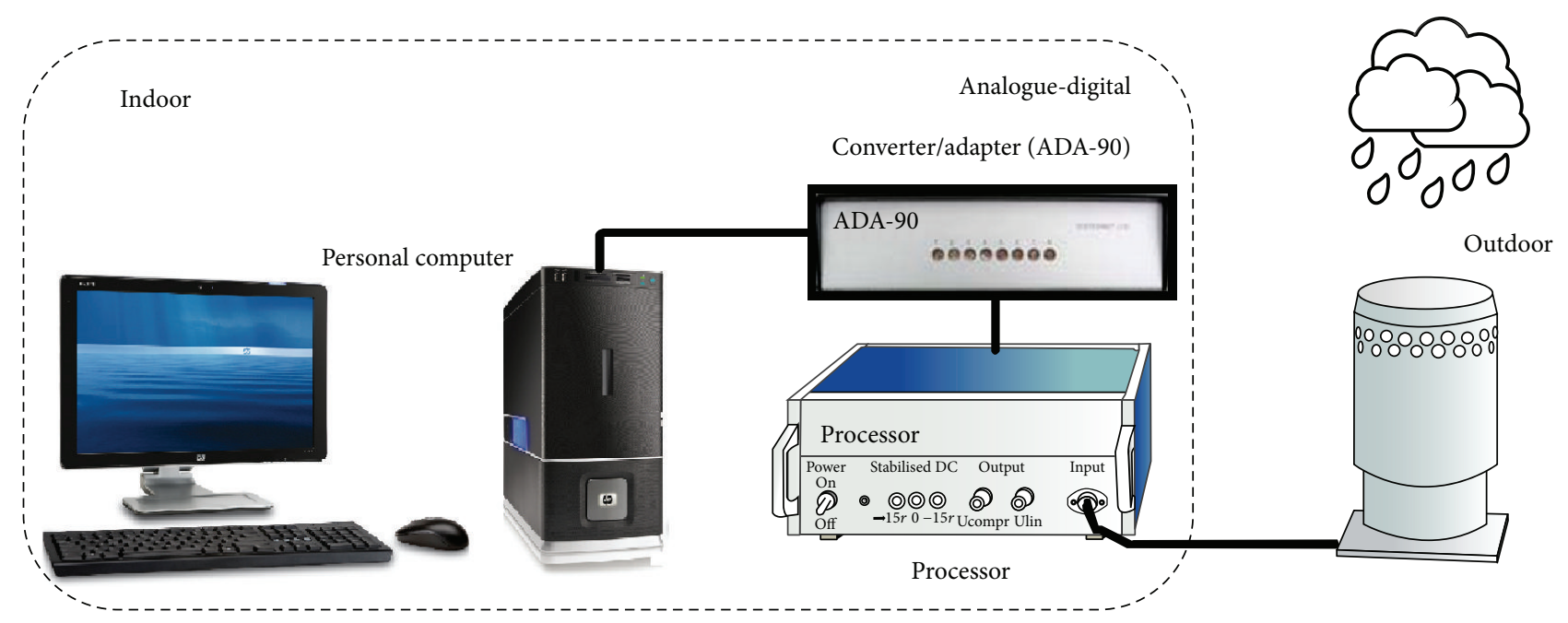

FIGURE 1: Measurement system for Joss-Waldvogel disdrometer (JWD, RD-69) installed at Universiti Teknologi Malaysia (UTM) campus in Kuala Lumpur, Malaysia.

indoors. This transducer of the disdrometer transforms the vertical momentum of a mechanical impulse into an electrical pulse whose amplitude is a function of the drop diameter. The processor unit then filters out the acoustic noise affecting the transducer and processes the electrical signal from the raindrops. The ADA-90 accepts the drop pulses from the transducer and converts them into a digital signal.

The disdrometer has a cross-sectional sampling area of $S=5000 \mathrm{~mm}^{2}$ and classifies drops into 20 classes ranging from 0.3 to $5.3 \mathrm{~mm}$ based on their size. The rainfall rate observed via the JW disdrometer (expressed in $\mathrm{mm} / \mathrm{hr}$ ) can be calculated using (1), which involves a simple summation over the various drop size classes [36]:

$$
R=\frac{3600 \pi}{6 S T} \sum_{i=1}^{20} D_{i}^{3} n_{i}
$$

where $n_{i}$ is the number of raindrops whose diameters fall within the $i$ th class (with mean diameters $D_{i}$ ).

The measured rain drop size distribution $N\left(D_{i}\right)\left(\mathrm{m}^{-3}\right.$. $\mathrm{mm}^{-1}$ ) is calculated as [36]

$$
N\left(D_{i}\right)=\frac{n_{i} \times 10^{6}}{v\left(D_{i}\right) \times S \times T \times \Delta D_{i}},
$$

where $\Delta D_{i}$ represents the width of each drop-size class and $v\left(D_{i}\right)$ is the terminal velocity of the rain drops in $\mathrm{m} / \mathrm{s}$, which has been extracted from the work of Gunn and Kinzer [37].

In order to obtain appreciable and reliable data for this work, each minute of raindrop spectra has been carefully processed, and to avoid sampling problems, each one-minute sample containing fewer than 10 drops or having a rain rate less than $0.1 \mathrm{~mm} / \mathrm{h}$ has been excluded and disregarded as noise [10]. It is worth mentioning that these raindrop spectra are analyzed without considering their seasonal or diurnal variations, with the aim of preserving the overall characteristics of the raindrop spectra in this region and achieving reliable statistical results. In addition, the ratio between the
TABLE 1: Recorded-to-total time ratio in percent on a yearly basis for the period 1992 to 1994 in Kuala Lumpur.

\begin{tabular}{lc}
\hline Time period & Recorded-to-time ratio [\%] \\
\hline 1992 & 99.6 \\
1993 & 99.3 \\
1994 & 99.3 \\
\hline $1992-1994$ & 99.4
\end{tabular}

number of minutes corresponding to the recorded rainfall rate and the total number of minutes in the observation period has been calculated as an index of data availability, which is referred to as recorded-to-total time, as shown in Table 1 on the yearly basis. For the complete three-year period, a recorded-to-time ratio of $99.4 \%$ has been achieved.

In addition, a well-known issue of the JWD RD-69 disdrometer in measuring the DSD is the reduced sensitivity at drops smaller than $1 \mathrm{~mm}$ under heavy rain conditions, due to the so-called "disdrometer dead time." In the present study, dead time correction has been applied based on the empirical algorithm of an in-house software package proposed by Sheppard and Joe [38]. The algorithm aims to improve the accuracy by up to $10 \%$. Moreover, environmental sources of error, such as acoustic noise and wind turbulence, are minimized via installing the instrument on the rooftop of a low building.

Based on the data processing and quality assessment procedures underlined above, the DSD database is now believed to be reliable and fully representative of real raindrop spectra in this region, making it useful for the characterization and modeling of the DSD.

\section{Rainfall Characteristics in the Peninsula Malaysia}

As previously mentioned, geographical area is one of the factors affecting the intrinsic variability of the DSD. This 


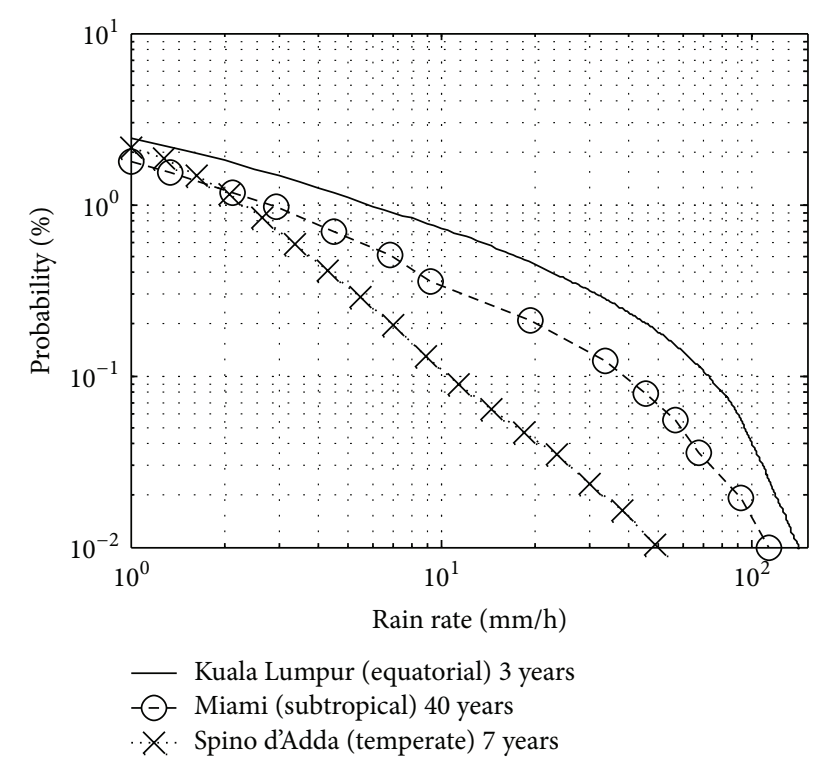

Figure 2: CCDF of rainfall rate from different climatology regions: Kuala Lumpur (1992-1994) equatorial, Miami (40 Year) subtropical, and Spino d'Adda (1994-2000) temperate.

phenomenon is particularly significant in equatorial areas where the characteristics features of the DSD are influenced by the peculiarities of the local climatology and topography. Malaysia has such an equatorial climate; it is characterized by high humidity, a uniform temperature, and lavish rainfall as compared to temperate and subtropical regions, as evidenced by Figure 2 . This figure compares the complementary cumulative distribution functions (CCDFs) of the rain rates from three climatological regions, namely, the equatorial (Kuala Lumpur), subtropical (Miami), and temperate regions (Milan, Italy). The figure depicts an extremely high rainfall amount for the equatorial region as compared to the other two regions.

Even though there is no alternation of summer and winter, as in temperate regions, due to the uniform temperature throughout the year, the climate of Peninsula Malaysia has a seasonal rhythm caused by changes in airstream direction and speed across Peninsula Malaysia. The year can generally be categorized into two monsoonal and two transitional seasons: the north-east monsoon (December to March), the south-west monsoon (June to September), and two intermonsoon seasons (April to May and October to November). Such features are clearly illustrated in Figure 3. The comparison of mean monthly rainfall accumulation between the long-term rain gauge measurements of the Malaysian Meteorological Department and that from the disdrometer database used in this work confirmed the seasonal pattern in this location.

Nevertheless, as far as the DSD is concerned, seasonal variations in this particular area are beyond the scope of this work because the main objective is to focus on the general features of the DSD. However, detailed work related to this topic can be found in [29].
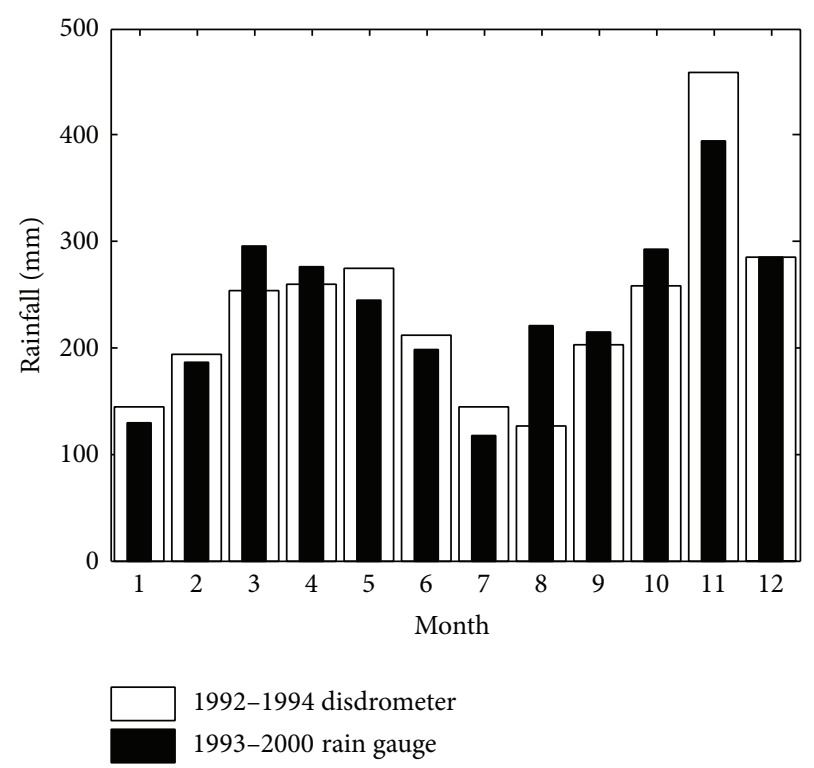

FIGURE 3: Comparison of monthly rainfall accumulation between disdrometers: (1992-1994) and meteorological rain gauge (19932000).

\section{Results and Discussion}

This section presents the natural DSD characteristics in equatorial Kuala Lumpur, followed by the statistical properties of the Gamma and normalized Gamma model parameterizations in order to identify the most adequate distributions that can properly model the DSD's main features in this particular region. Finally, the validity of those models has been assessed by means of a comparison of rain rates that were calculated directly from the disdrometer data and the models.

4.1. Disdrometer Observation. The summary of the average measured drop counts at different bins for rain rates ranging from 0.1 to $200 \mathrm{~mm} / \mathrm{h}$ is listed, along with the thresholds for the drop size bins, in Table 2. As can be observed in this table, the rain drops tend to increase in number from the lower-drop-size bins to the higher-drop-size bins, which corresponds to the larger diameter of rain drops as the rain rate increases, as evidenced by Figure 4 . In fact, the same characteristic has also been observed in results reported in Singapore [7]. Moreover, Ulbrich [3] also pointed out the rarity of small rain drops in tropical rainfall, which is not caused solely by the dead time problem of JWD or the insufficient natural correction for acoustic noise, as highlighted by Zawadzki and De Agostinho Antonio [32].

Figure 5 further illustrates an example of the average drop size density distribution as a function of the average rain rate.

\subsection{DSD Models and the Statistical Properties of Their Param-} eters. The DSD model implies choosing a DSD profile that describes the distribution of drop size and thus rain intensity in a simple way. In this respect, the most widely used models are the Gamma model and the normalized Gamma model. In fact, a key feature of a DSD model is that it should 


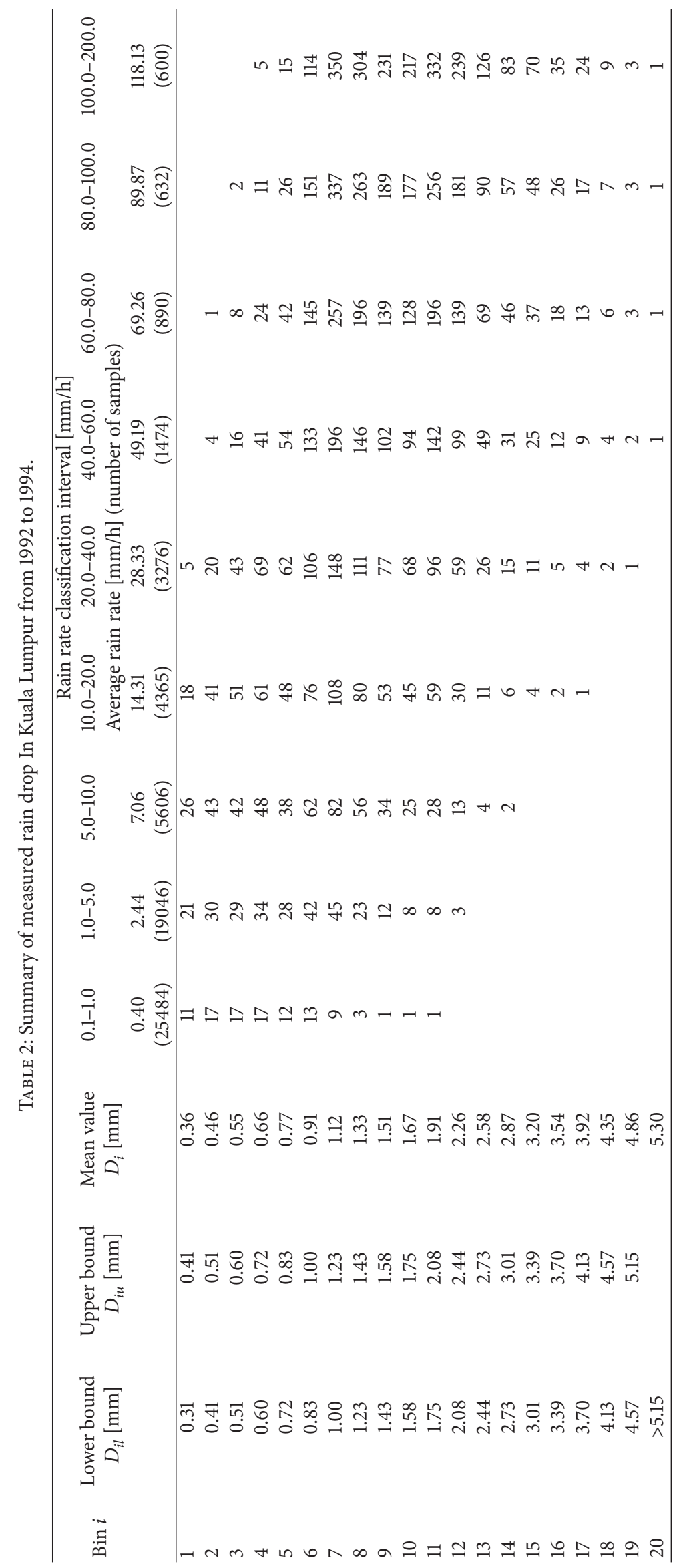




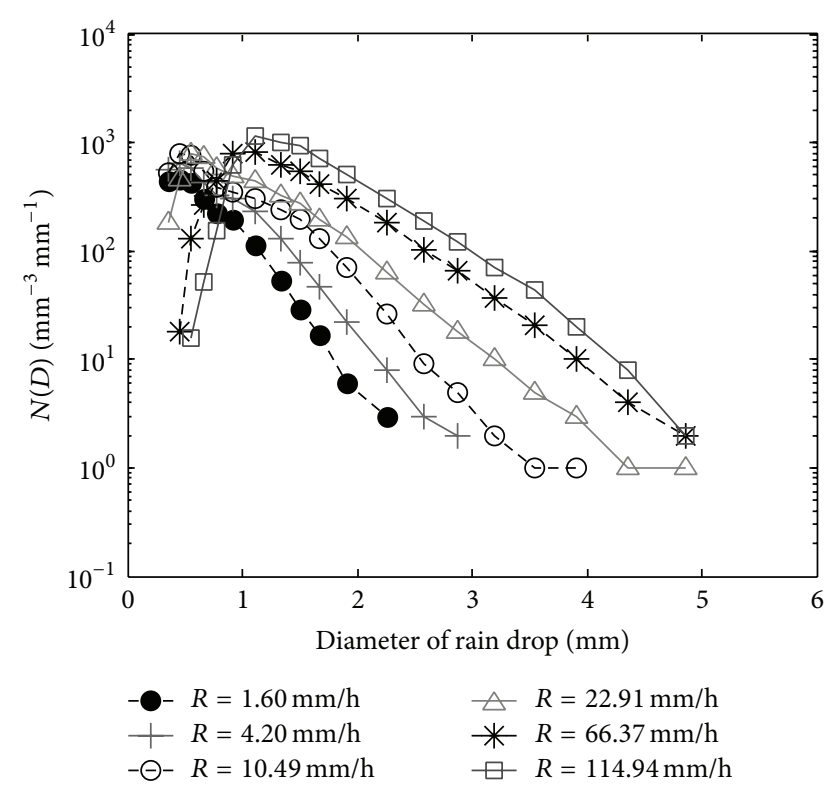

FIgURE 4: Drop side distribution of average rain rates in Kuala Lumpur from years 1992-1994.

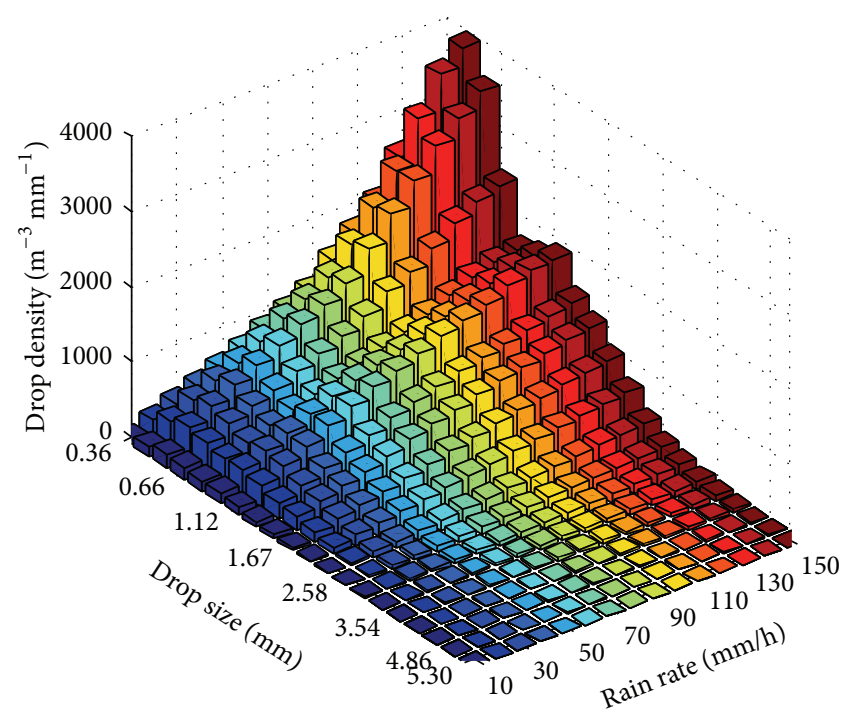

FIGURE 5: Average drop size distribution as a function of rain rate.

be able to reproduce the statistical properties of local DSD parameters in order to assess the same parameters when they are inferred from remote sensing instruments, such as ground weather radar or space-borne radar. This subsection presents the results regarding the statistical properties of both model parameters derived from the Kuala Lumpur disdrometer as well as the relationships between these parameters.

4.2.1. Gamma Model. As stated earlier, the Gamma distribution model [3] is the most commonly accepted model in describing the natural variation of the DSD. In fact, with three parameters $\left(N_{o}, \mu\right.$, and $\left.\Lambda\right)$, the Gamma model is capable of describing a broader variation in rain drop spectra than any other distribution (i.e., exponential). These parameters can be identified through curve fitting, maximum likelihood estimation (MLE), or method of moment (MoM) [15]. In this work, MoM is considered due to its ability to fit proportionally to the moment of integral rainfall parameters (i.e., the rain rate is proportional to the 3.67 th moment, while radar reflectivity factor is the 6th moment of the drop spectrum). Various combinations of the moments are available for the DSD parameter estimation, as mentioned above. Due to the degraded sensitivity of the disdrometer, this study employed three moments (3rd, 4th, and 6th moments) to model the DSD in this region, following most of the researchers in heavy rain regions [7, 10-12]. In general, the $x$ th moment of the DSD, $M_{x}$, is expressed as

$$
M_{x}=\frac{N_{o}}{\Lambda^{\mu+x+1}} \Gamma(\mu+x+1),
$$

where $\Gamma(x)$ is the complete Gamma function. In this work, $M_{x}$ is obtained through the experimental data

$$
M_{x}=\frac{N_{t}}{n} \sum_{i=1}^{n} D_{i}^{x}
$$

where $n$ corresponds to the number of samples and $N_{t}$ is the particle number concentration.

By using $x_{1}=3, x_{2}=4, x_{3}=6$, the three Gamma parameters may be obtained as [11]

$$
\begin{gathered}
\mu=\frac{11 G-8+\sqrt{G(G+8)}}{2(1-G)} \quad \text { with } G=\frac{M_{4}^{3}}{M_{3}^{2} M_{6}}, \\
\Lambda=(\mu+4) \frac{M_{3}}{M_{4}}, \\
N_{o}=\frac{\Lambda^{\mu+4} M_{3}}{\Gamma(\mu+4)} .
\end{gathered}
$$

Figure 6 shows the histograms of the shape parameter $\mu$ for the Gamma model derived from (7) over the three years of disdrometer data. As can be observed from the figures, the mean value for the shape parameter $\mu$ obtained for the three years of DSD data in Kuala Lumpur is 6.76. This value is consistent with the results of [39] in Japan; their mean $\mu$ value is 6.71. In fact, this is also close agreement with the result obtained in Singapore (about $350 \mathrm{~km}$ from Kuala Lumpur) [33], which suggested the choice of a $\mu$ value ranging from 3 to 5 . However, Tokay and Short [10] found a mean $\mu$ value of 9.82 for the tropical ocean of Kapingamarangi. It should be noted that the estimation of $\mu$ is the most critical because it is strongly affected by disdrometer data quality [40]. Such consistent results in several locations from other parts of the world indirectly confirm the validity of the database used in this study.

The slope parameter $\Lambda$ (see Figure 7) and the intercept parameter $\log _{10} N_{o}$ (see Figure 8) also follow the same trend of observation as observed in [39]. The mean value of $\Lambda$ is 7.33 , which is very similar to the result obtained in Japan, a value of 7.74 [39], but a slightly higher value was obtained in the tropical ocean of Kapingamarangi, a mean 


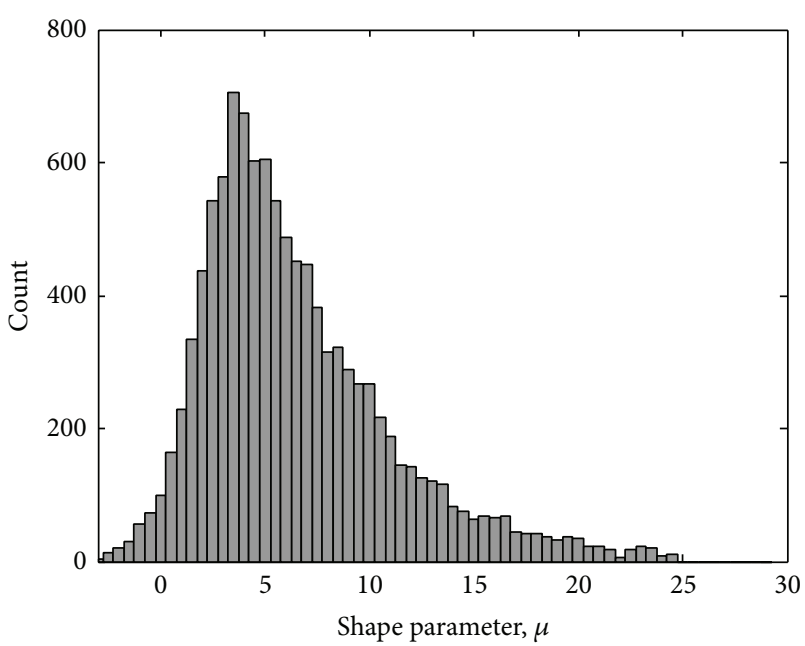

Figure 6: Histogram of estimated shape parameter $\mu$ for Gamma model.

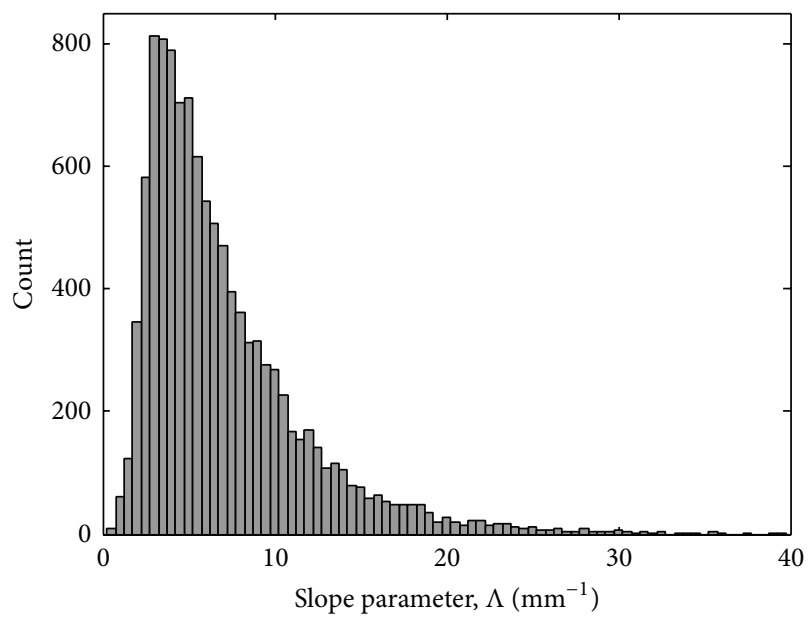

FIgURE 7: Histogram of estimated slope parameter $\Lambda$ for Gamma model.

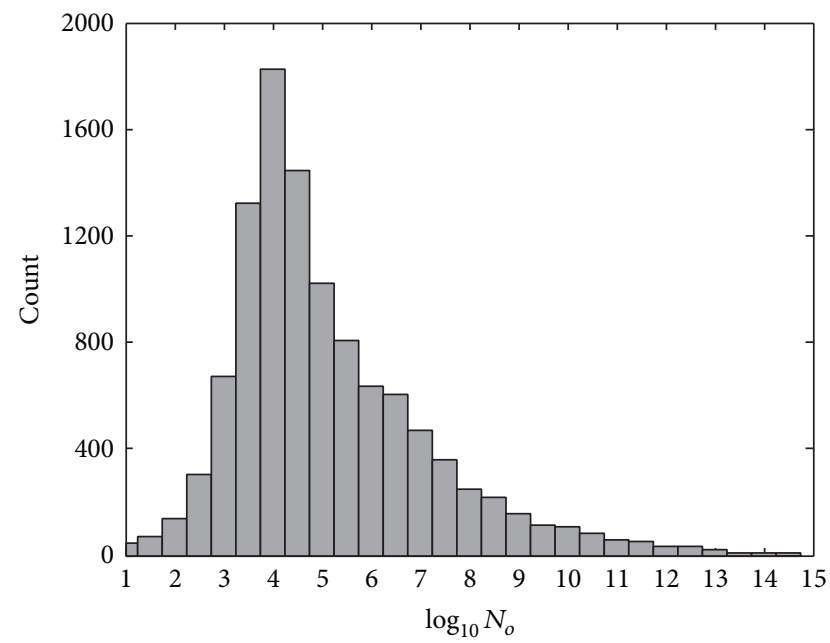

FIGURE 8: Histogram of estimated $\log _{10} N_{o}$ parameter for Gamma model. value of $10.6 \mathrm{~mm}^{-1}$ [10]. In addition, as shown in Figure 8, the intercept parameter $\log _{10} N_{o}$ reported a mean value of $5.39 \mathrm{~mm}^{-1} \mathrm{~m}^{-3}$, which is also close to the mean value of $6.09 \mathrm{~mm}^{-1} \mathrm{~m}^{-3}$ obtained by Kozu [39].

Apart from the statistical results, the relationships between the three parameters of Gamma DSD are also evaluated. Figures 9(a)-9(c) show the scatter plots of their relationships, together with the corresponding fitting. In the past, several studies have investigated the slope-shape relationship for Gamma DSD with the aim of changing it from a three-parameter to a two-parameter model $[4,18,19]$.

Recently, an empirical $\mu-\Lambda$ relationship from Singapore was reported in [33] as follows:

$$
\Lambda=0.036 \mu^{2}+0.432 \mu+1.507 .
$$

In addition, it should be noted that several empirical $\mu$ - $\Lambda$ relationships are proposed based on the DSD observations in their respective locations. However, in this work, we only compared our results with the empirical relationship from Singapore, which is in the same climatic area and is near to our observation sites, as plotted in Figure 9(a). The corresponding equation is given by

$$
\Lambda=0.041 \mu^{2}+0.310 \mu+1.740 .
$$

As can be observed from Figure 9(a), the trends of the $\mu$ $\Lambda$ fit in Malaysia and Singapore are very similar which could be explained by both sites being located in the same climatological region because most rain events considered are convective events. Furthermore, the relationships of between $N_{o}$ along with the relationships of $\mu$ and $\Lambda$ are also plotted in Figures 9(b) and 9(c). Obviously, the $\log _{10} N_{o}-\mu$ relationship is also found via the second-degree polynomial fitting, given as

$$
\log _{10} N_{o}=0.0197 \mu^{2}+0.1197 \mu+3.649 .
$$

In addition, it is clear from Figure 9(c) that the $\log _{10} N_{o}-\Lambda$ relationship can be described by a linear relation using the following expression:

$$
\log _{10} N_{o}=0.4638 \Lambda+2.716
$$

4.2.2. Normalized Gamma Model. The normalized Gamma distribution has been widely accepted in the meteorology community due to the fact that its parameters $\left(N_{w}, \mu\right.$, and $D_{m}$ ) are independent parameters that provide the most physical based estimation of the DSD, specifically representing the concentration, the width of the drop shape, and the mass-weighted mean diameter. In fact, the most significant advantage of this normalization approach is its ability to neglect the assumption of the shape of the raindrop spectra while effectively describing the volumetric size distribution of raindrops for wide range of rain rates [21, 22]. This model can be described as [22]

$$
N(D)=N_{w} \cdot f(\mu) \cdot\left(\frac{D}{D_{m}}\right)^{\mu} \cdot e^{\left[-(4+\mu) \cdot\left(D / D_{m}\right)\right]},
$$




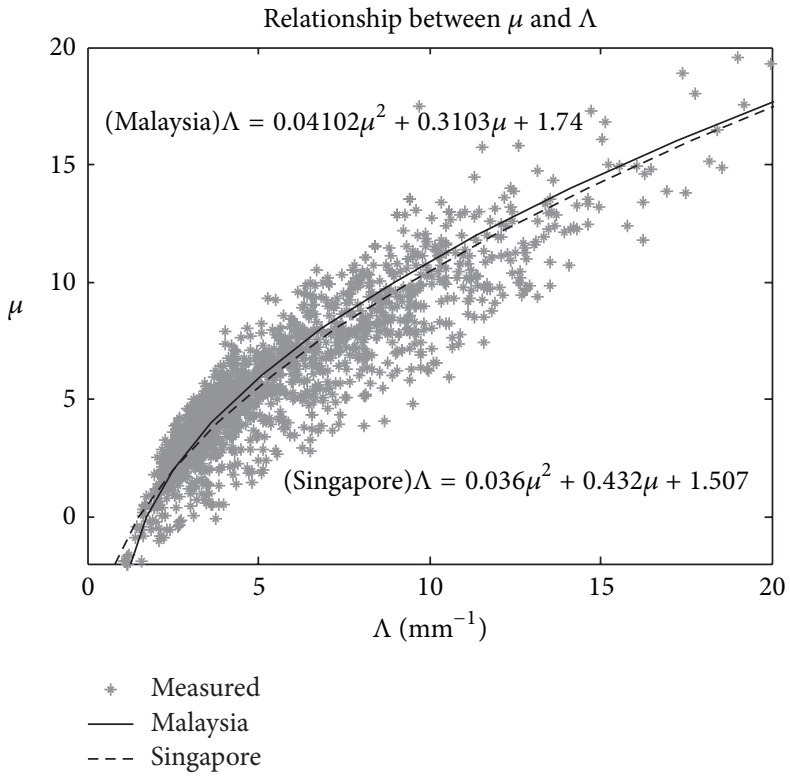

(a)

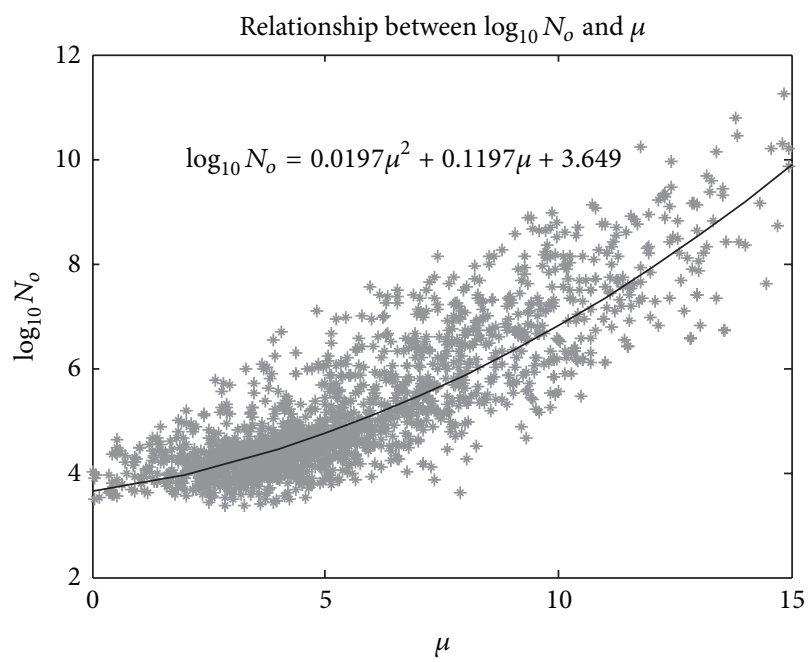

(b)

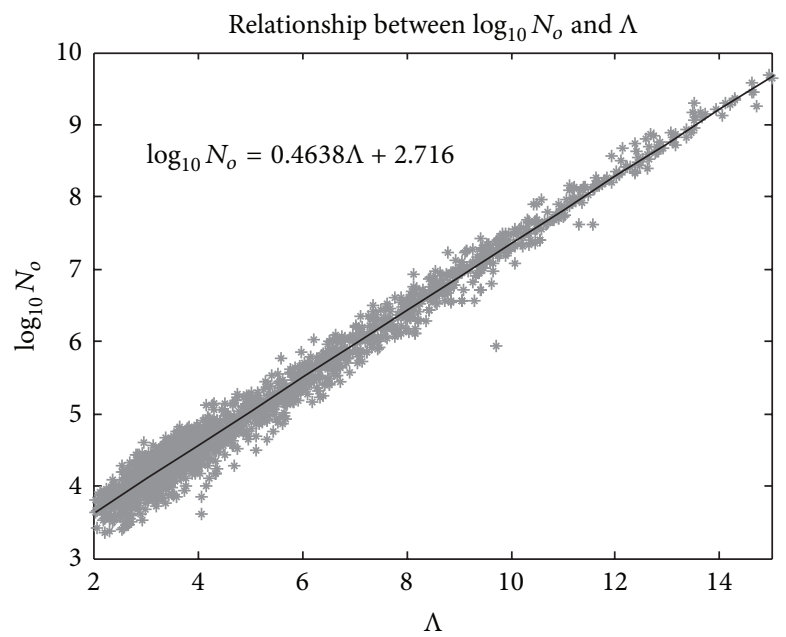

(c)

FIGURE 9: (a) Relations between $\mu$ - $\Lambda$ values obtained from disdrometer data and their corresponding fit. The curve obtained through empirical relationship from Singapore is also included for comparison. (b) Relation between $\log _{10} N_{o}-\mu$ values obtained from disdrometer data and their corresponding fit. (c) Linear Relation between $\log _{10} N_{o}-\Lambda$ values obtained from disdrometer data and their corresponding fit.

where $N_{w}$ (units per cubic meter per millimeter), $\mu$, and $D_{m}$ $(\mathrm{mm})$ are the intercepts, the shape, and the mass weighted mean diameter parameters, respectively, and $f(\mu)$ is given by

$$
f(\mu)=\frac{6}{4^{4}} \cdot\left[\frac{(4+\mu)^{(4+\mu)}}{\Gamma(4+\mu)}\right]
$$

$D_{m}$ can be calculated as the ratio between the fourth and third empirical moments of the DSD:

$$
D_{m}=\frac{M_{4}}{M_{3}}
$$

while $N_{w}$ can be derived as

$$
N_{w}=\frac{256}{6} \cdot \frac{M_{3}^{5}}{M_{4}^{4}}
$$

The parameters $N_{w}$ and $D_{m}$ are estimated by the Gamma MoM method [15], whereas $\mu$ can be inferred either by means of the Gamma MoM method or the MLE method [40]. Specifically, the $\mu$ of the Gamma MoM method can be derived as follows:

$$
\mu_{\mathrm{MoM}}=\frac{(7-11 \eta)-\sqrt{(7-11 \eta)^{2}-4 \cdot(\eta-1) \cdot(30 \eta-12)}}{2 \cdot(\eta-1)},
$$




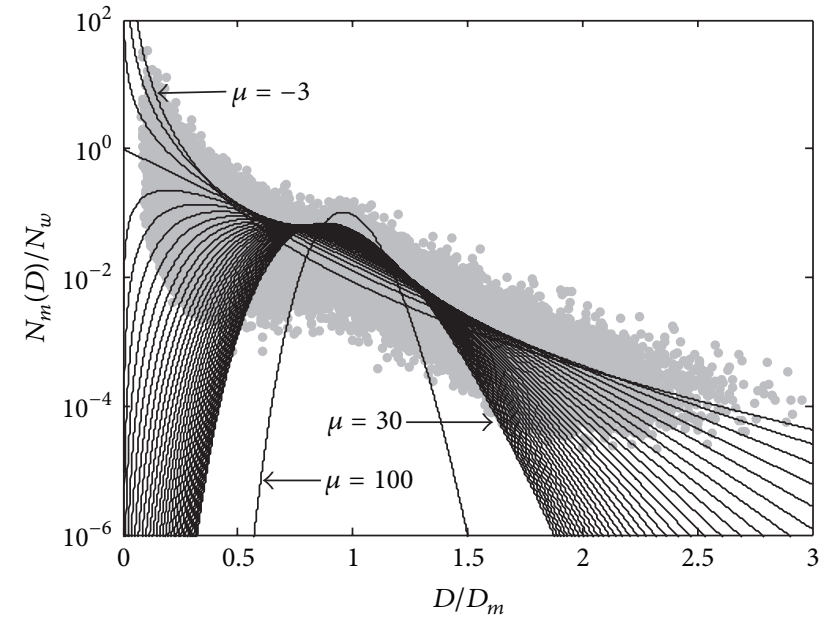

FIGURE 10: The scaled DSD $N_{m}(D) / N_{w}$ versus normalized diameter parameter $D / D_{m}$ of the measured samples (gray dots). Solid lines indicate the normalized Gamma distribution for values of $\mu$ ranging between -3 and 30 at step of 1 . The curve of $\mu=100$ is also included.

where $\eta$ can be defined from the moments $M_{2}, M_{4}$, and $M_{6}$ via the procedure suggested by [15]

$$
\eta=\frac{M_{4}^{2}}{M_{2} \cdot M_{6}} .
$$

As a further motivation to understand the DSD's fit with the normalized Gamma model, the superimposition of the $\mu$ values on the scaled data, $N_{m}(D) / N_{w}$, versus the normalized drop diameter, $D / D_{m}$, is shown in Figure 10. The range of $\mu$ is bounded by the family of normalized Gamma functions, which implies the effectiveness of the DSD fit [24]. The results clearly indicate that the measured DSDs are well bounded by the scaled Gamma functions because the superimposed $\mu$ varies over a range from -3 to 30 , which is consistent with the findings reported by [24, 40,41]. In particular, analyses carried out in heavy rain areas, such as Sumatra, suggest the same range of $\mu$ values, while Montopoli et al. [40], who analyzed a large dataset of DSD measurements collected with JWD in the UK, Greece, Japan, and the US, reported that values of $\mu$ varied over a range of -3 to 10 . Bringi et al. [24] suggested a range of $\mu$ that is slightly wider, spanning from -3 to 15 , which was observed through the South China Sea Monsoon Experiment.

Apart from the Gamma MoM estimation, as mentioned earlier, $\mu$ also can be estimated by the MLE method, which minimizes the absolute deviation between the measured DSDs and the normalized Gamma distribution using with the following expression [40]:

$$
\mu_{\mathrm{MLE}}=\min _{\mu}\left\{\sum_{i=1}^{20}\left[N_{m}\left(D_{i}\right)-N\left(D_{i}, \mu\right)\right]^{2}\right\} .
$$

In order to have a clearer view of the range of $\mu$, the histogram distribution of this parameter was obtained by means of the MoM and MLE methods and illustrated in Figures $11(\mathrm{a})$ and $11(\mathrm{~b})$, respectively. It is worth noting that these plots tend to agree with each other fairly well, even though the distributions of MLE $\mu$ values have a slightly larger spread than the MoM $\mu$ values, with the mean $\bar{\mu}$ and standard deviation $\sigma$ values equal to 7.95 and 5.13, respectively, while $\bar{\mu}=6.14$ and $\sigma=4.53$ for the $\operatorname{MoM} \mu$.

In addition to $\mu$, Figures 12 and 13 show the histograms of the parameters $D_{m}$ and $\log _{10} N_{w}$, which were estimated by the Gamma MoM from (16) and (17), respectively.

From the histogram of $D_{m}$, it is evident that the diameters of the drop spectra are dominated by a medium drop size, which was distributed from $1 \mathrm{~mm}$ to $2.5 \mathrm{~mm}$ with a mean $\overline{D m}$ of $1.74 \mathrm{~mm}$ and a $\sigma$ of 0.59 . This result is slightly larger than the observation made by Tokay and Short [10] in the tropical ocean $(\overline{D m}=1.41 \mathrm{~mm})$.

In addition to the statistical distribution, to further understand the relationship between these normalized Gamma parameters, scatter plots of $D_{m}$ versus $\log _{10} N_{w}$, $D_{m}$ versus $\mu$, and $\log _{10} N_{w}$ versus $\mu$ are shown in Figures 14(a)-14(c), respectively. We noticed that the $D_{m}$ values are somewhat inversely proportional to the $\log _{10} N_{w}$ values, which seems to be in good agreement with scatter plots from the large set of disdrometer measurements collected in other parts of the world [40]. The other two scatter plots $\left(D_{m}-\mu\right.$ and $\log _{10} N_{w}-\mu$ ) show little correlation.

The summarized major statistical quantities of these two DSD models' parameters are listed in Table 3 for the sake of clarity.

As can be seen from the statistics indicators in Table 3, low positive skewness values have been observed for all DSD parameters, which indicates that most of the parameter values tend to be distributed to the left of the mean values. On the other hand, the moderate kurtosis values for all model parameters confirmed that the datasets were aggregated near the mean, except for the shape parameter $\Lambda$ in the Gamma model, which shows a higher kurtosis value, indicating the higher variability of this parameter.

In addition, it is worth noticing the values of the statistic indicators for the normalized Gamma model, which are consistent with those found by Montopoli et al. [41] (i.e., in their work, the mean of shape parameter $\mu$ is equal to 7.59 , the mean of $D_{m}$ is 1.76 , the skewness $D_{m}$ is 1.83 , and the mean of $\log _{10} N_{w}$ is 3.96, which are pretty close to the values found in this study).

4.3. Rain Rate Estimation. One of the main objectives in estimating and modeling the DSDs is to improve the estimation accuracy of meteorological quantities such as rain rate estimation and the radar reflectivity factor. In this subsection, the performances of the three-parameter Gamma and normalized Gamma models are assessed by means of comparing the estimated rain rate with the rain rate measured from the disdrometer.

In order to quantitatively assess the performance of the models in estimating the rain rate, the following error figure is considered:

$$
\varepsilon=100 \frac{R_{e}-R_{m}}{R_{m}},
$$




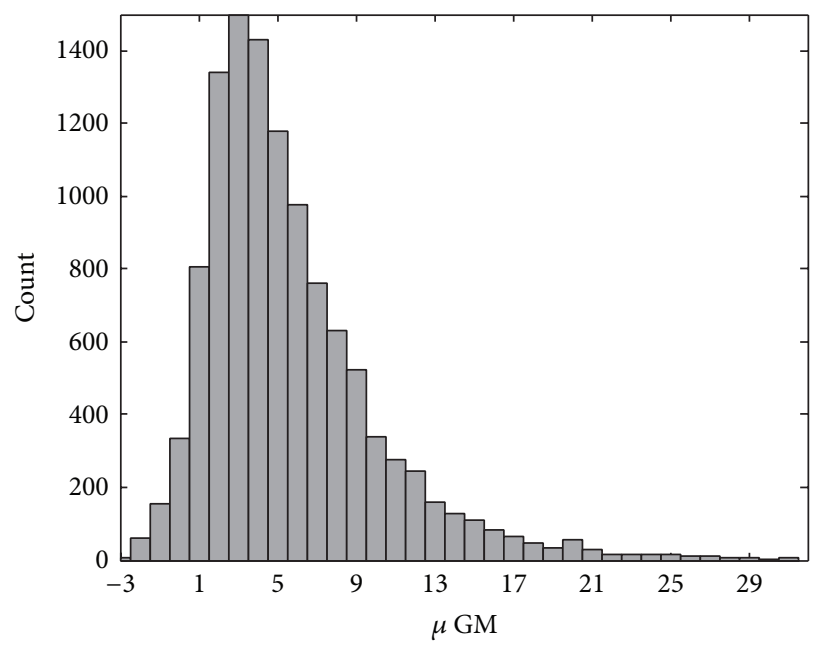

(a)

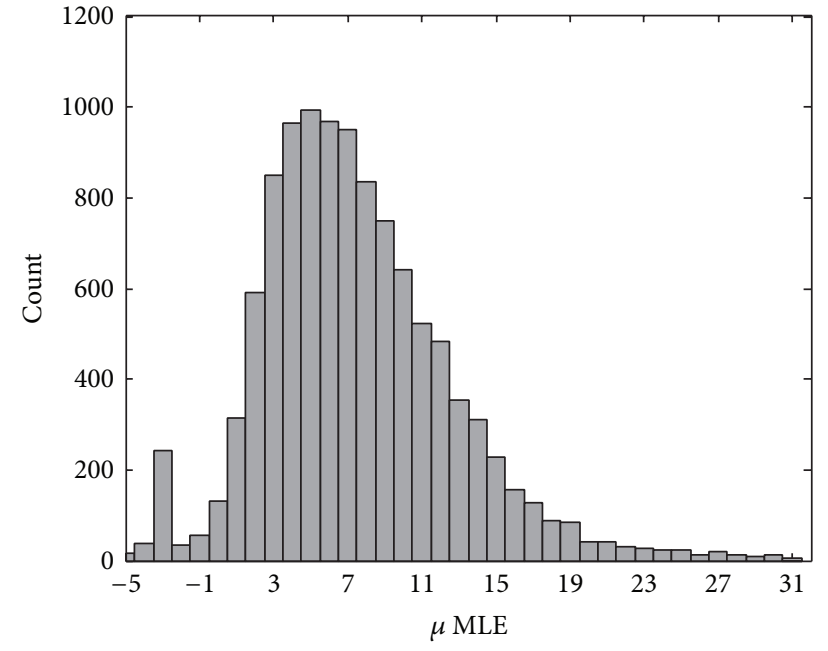

(b)

FIGURE 11: (a) Histogram of estimated $\mu$ parameter by means of Gamma moment method (MoM) for normalized Gamma model. (b) Histogram of estimated $\mu$ parameter by means of maximum likelihood estimation (MLE) method for normalized Gamma model.

TABLE 3: Statistics of DSD parameters derived from disdrometer data (January 1992-December 1994, 1 min rain rate data, total number of data $=61384)$.

\begin{tabular}{lccccccc}
\hline Model & Parameter & Mean & SD & Min & Max & Kurtosis & Skewness \\
\hline \multirow{3}{*}{ Gamma } & $\log N_{o}$ & 5.39 & 2.04 & 1.02 & 14.95 & 5.06 & 1.27 \\
& $\Lambda$ & 7.34 & 4.89 & 0.79 & 59.19 & 12.39 & 2.28 \\
& $\mu$ & 6.76 & 4.56 & -2.60 & 24.98 & 4.47 & 1.15 \\
\hline \multirow{3}{*}{ Normalized Gamma } & $\log N_{w}$ & 3.52 & 0.50 & 0.81 & 4.87 & 4.56 & -0.76 \\
& $D_{m}$ & 1.74 & 0.59 & 0.67 & 4.95 & 5.59 & 1.33 \\
& $\mu(\mathrm{GM})$ & 6.14 & 4.53 & -2.17 & 31.95 & 7.07 & 1.67 \\
& $\mu(\mathrm{MLE})$ & 7.95 & 5.13 & -4.91 & 31.75 & 4.63 & 0.80 \\
\hline
\end{tabular}

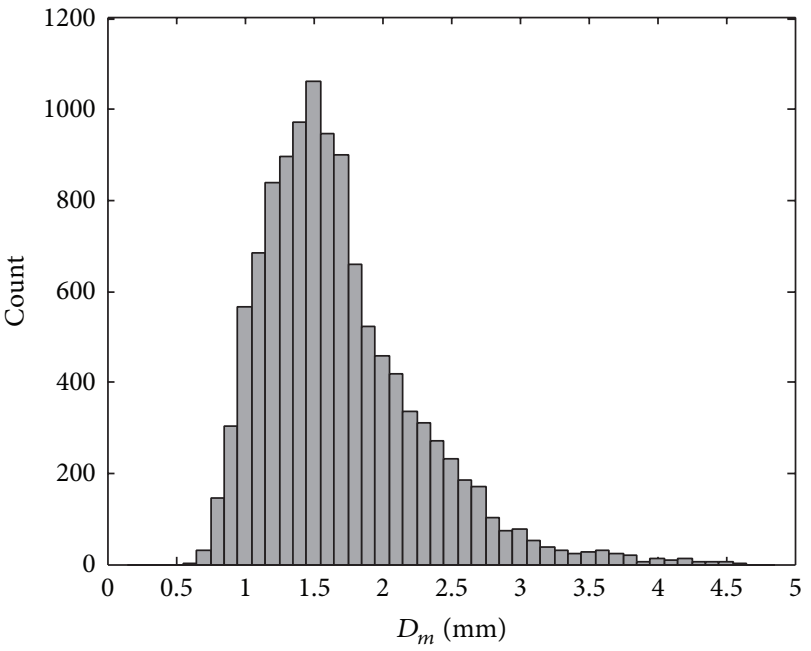

FIGURE 12: Histogram of estimated $D_{m}$ parameter for normalized Gamma model.

where $R_{e}$ and $R_{m}$ are the rain rate values from the estimate and disdrometer measurement, respectively. Table 4 summarizes the overall performance results from each minute of

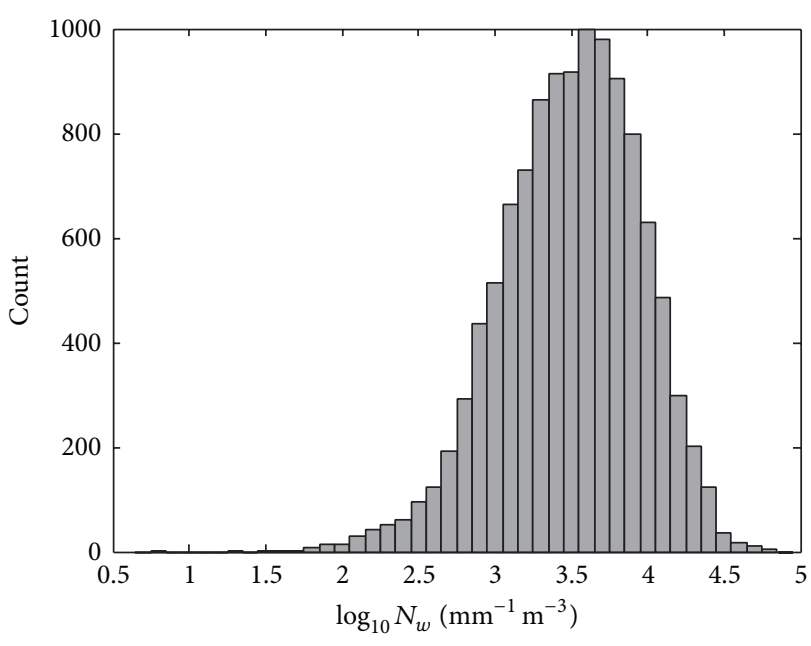

FIGURE 13: Histogram of estimated $\log _{10} N_{w}$ parameter for normalized Gamma model.

estimated rain rate, along with the calculated mean $\varepsilon_{\text {mean }}$, standard deviation $\varepsilon_{\text {std }}$, and root mean square $\varepsilon_{\text {rms }}$ errors.

As expected, the results clearly show the excellent performance of the normalized Gamma model when the shape 


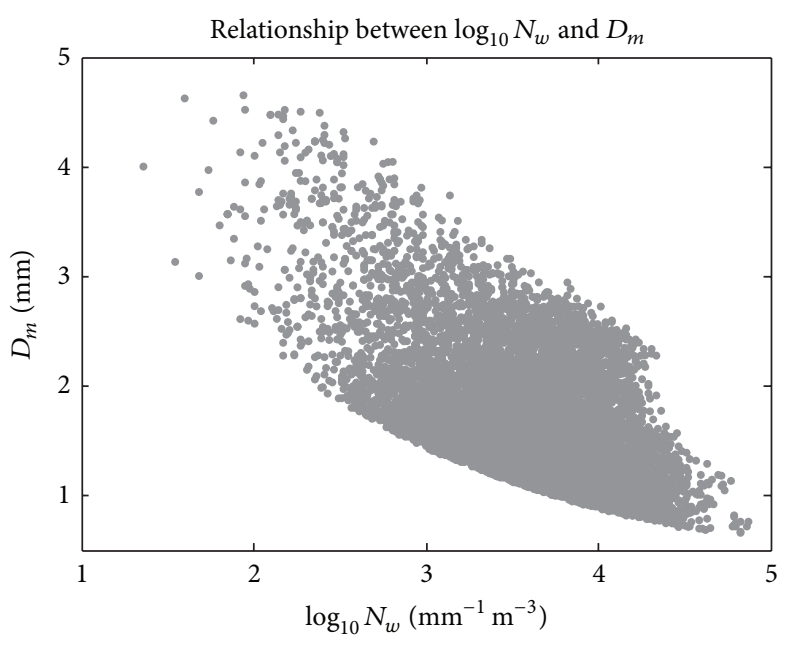

(a)

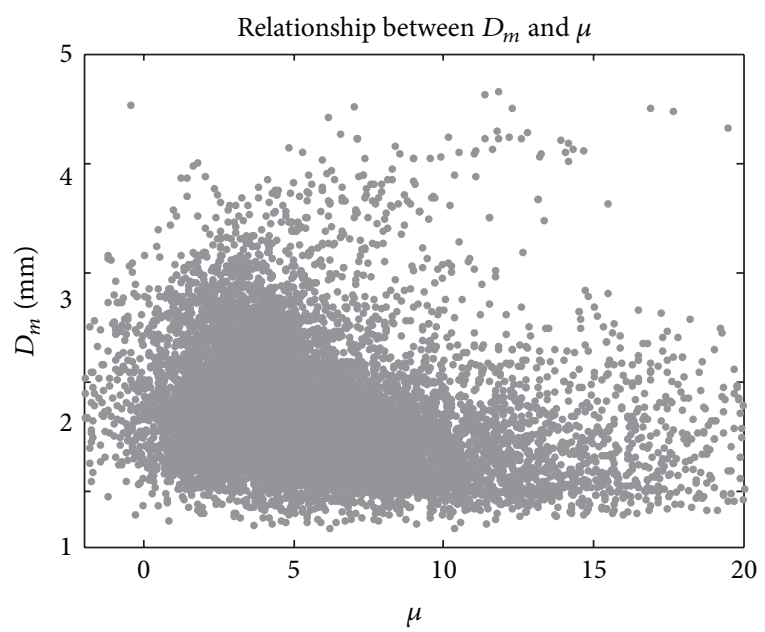

(b)

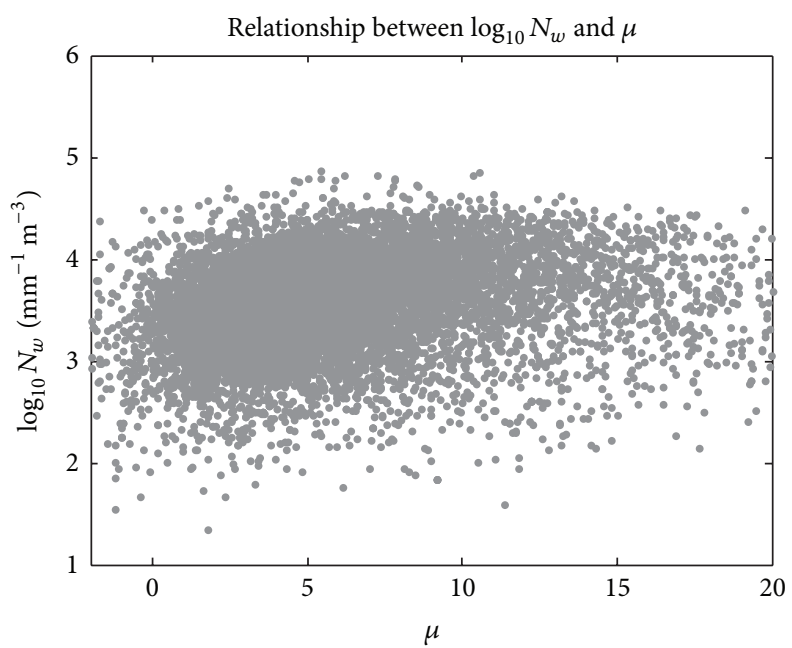

(c)

FIGURE 14: (a) Scatter plots of estimated normalized Gamma DSD parameters: $D_{m}-\log _{10} N_{w}$ values. (b) Scatter plots of estimated normalized Gamma DSD parameters: $D_{m}-\mu$ values. (c) Scatter plots of estimated normalized Gamma DSD parameters: $\log _{10} N_{w}-\mu$ values.

TABLE 4: Result of test on rain rate estimation from various DSD models ( $\varepsilon$ in \%).

\begin{tabular}{lccc}
\hline Model & $\varepsilon_{\text {mean }}$ & $\varepsilon_{\text {std }}$ & $\varepsilon_{\text {rms }}$ \\
\hline Gamma & 0.65 & 12.19 & 12.21 \\
Normalized Gamma (Gamma moment) & 0.40 & 12.05 & 12.05 \\
Normalized Gamma (maximum likelihood) & 0.10 & 6.30 & 6.30 \\
\hline
\end{tabular}

parameter $\mu$ is obtained by the MLE method. Indeed, the MLE method is a more accurate technique than the Gamma Moment method, which has already been proven by the analysis of the three years of disdrometer measurements from Chilbolton, UK [26]. The remaining models show comparable performance, with slight differences in terms of $\varepsilon_{\text {rms }}$. It should also be noted that the estimation of $\mu$ is critical as it depends on the dominant rainfall-generating mechanism associated with local climatologic features, as well as the quality of the data collected from the disdrometer.
Examples of the model fitting of the disdrometermeasured DSD in Kuala Lumpur are shown in Figures 15(a) and 15(b) for two different rain rates.

\section{Conclusions and Future Works}

Three years of disdrometer measurements, collected in the equatorial region of Kuala Lumpur, Malaysia, have been analyzed to investigate the physical characteristics of natural $\mathrm{DSD}$, and the governing parameters of the Gamma and normalized Gamma models have been estimated. In particular, the gamma DSD parameters have been derived by means of the MoM method using three higher-order moments (3rd, 4th, and 6th) whereas the parameters of the normalized Gamma distribution have been inferred through the $\operatorname{MoM}(\mu$, $N_{w}$, and $D_{m}$ ) and MLE methods $(\mu)$. The statistical properties of these parameters are then demonstrated, along with the relationships between them. 


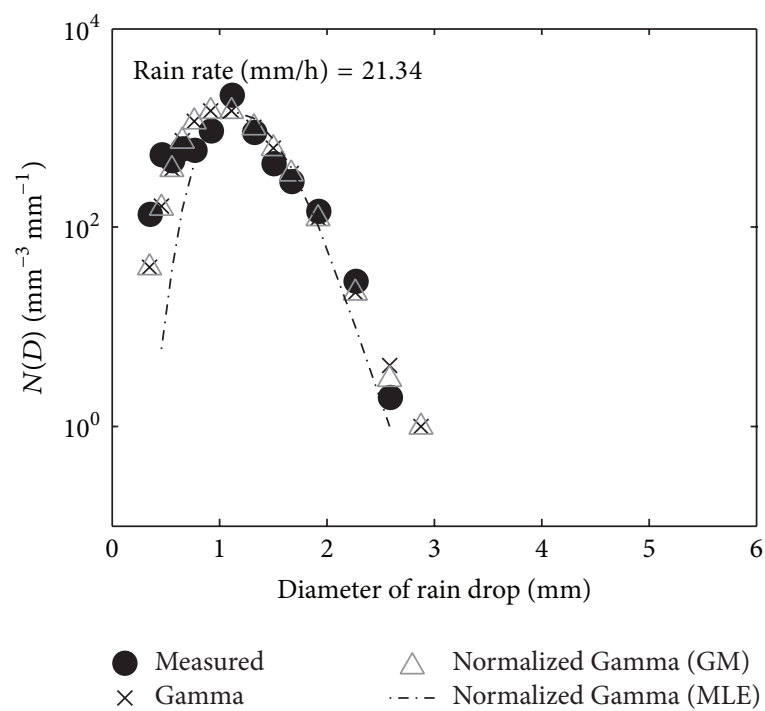

(a)

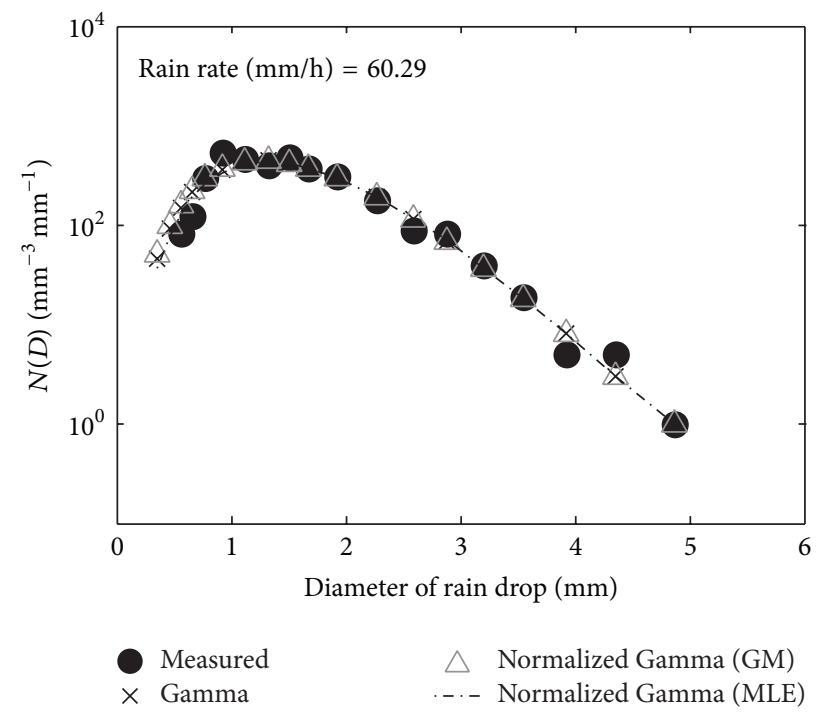

(b)

FigURE 15: (a) Examples of various models fitting of measured DSD at $21.34 \mathrm{~mm} / \mathrm{h}$. (b) As in (a), but for rain rate $60.29 \mathrm{~mm} / \mathrm{h}$.

The empirical $\mu-\Lambda$ relationship derived from the observed DSD in Kuala Lumpur is very close to that inferred from the Singapore DSD, which clearly implies the typical characteristics of DSDs in this convective equatorial climate. In addition to this feature, our observations revealed that medium drops diameter dominated over the large sample of observed DSD data; the mean of the mass-weighted mean diameter is $1.74 \mathrm{~mm}$, with a standard deviation of $0.59 \mathrm{~mm}$, and this mass weighted mean diameter is found to have an inverse correlation with the $\log _{10} N_{w}$ parameter.

Finally, the performances of the Gamma and the normalized Gamma models with two different shape parameters $\left(\mu_{\mathrm{MoM}}\right.$ and $\left.\mu_{\mathrm{MLE}}\right)$ have been evaluated in terms of rain rate estimation. The calculated rain rates from the models are compared with the rain rate derived directly from the measured DSD. As expected, the normalized Gamma model with $\mu_{\mathrm{MLE}}$ clearly shows excellent performance as compared to the other models.

The results presented in this study are unique in the sense of the equatorial areas examined, and they could thus provide crucial information regarding the application of remote sensing or the propagation community in this particular area. In fact, it is worth mentioning that such results are of practical relevance to providing crucial assessment parameters for the Global Precipitation Measurement (GPM) ongoing mission [42]. This mission, which aims to provide quantification of precipitation on a global scale from the satellite/space-borne radar observation, required the knowledge of precipitation microphysics process at ground level specifically focusing on the spatial variability of DSD [43-46].

Beside this, ground based weather radars, such as single polarization radar, polarimetric radars, and dual-frequency precipitation radar onboard the GPM core satellites, also rely on parameterizations of DSD model [47-49]. Hence, the results provided in this work offer a clear physical interpretation of rain microphysics in this particular heavy rain region for the above purposes.

\section{Conflict of Interests}

The authors declare that there is no conflict of interests regarding the publication of this paper.

\section{Acknowledgments}

This work was supported by the Ministry of Higher Education (MOE) under FRGS Vote 4F320, Universiti Teknologi Malaysia (UTM) under Research University Grants 04H10 and 07H50, and Postdoctoral Fellowship and Universiti Tun Hussein Onn Malaysia (UTHM) scholarship.

\section{References}

[1] J. S. Marshall and W. M. K. Palmer, "The distribution of raindrops with size," Journal of Meteorology, vol. 5, no. 4, pp. 165-166, 1948.

[2] J. O. Laws and D. A. Parsons, "The relation of rain-size to intensity," Transactions-American Geophysical Union, vol. 24, pp. 432-460, 1943.

[3] C. W. Ulbrich, "Natural variations in the analytical form of the raindrop size distribution.," Journal of Climate \& Applied Meteorology, vol. 22, no. 10, pp. 1764-1775, 1983.

[4] G. Zhang, J. Vivekanandan, and E. Brandes, "A method for estimating rain rate and drop size distribution from polarimetric radar measurements," IEEE Transactions on Geoscience and Remote Sensing, vol. 39, no. 4, pp. 830-841, 2001.

[5] V. Chandrasekar, W. Li, and B. Zafar, "Estimation of raindrop size distribution from spaceborne radar observations," IEEE Transactions on Geoscience and Remote Sensing, vol. 43, no. 5, pp. 1078-1086, 2005. 
[6] H. Y. Lam, L. Luini, J. Din, C. Capsoni, and A. D. Panagopoulos, "Investigation of rain attenuation in equatorial kuala lumpur," IEEE Antennas and Wireless Propagation Letters, vol. 11, pp. 1002-1005, 2012.

[7] L. S. Kumar, Y. H. Lee, and J. T. Ong, "Truncated gamma drop size distribution models for rain attenuation in Singapore," IEEE Transactions on Antennas and Propagation, vol. 58, no. 4, pp. 1325-1335, 2010.

[8] J. Joss and A. Walvogel, "A spectrograph for automatic measurement of rainfall," Geofisica Pura e Applicata, vol. 68, pp. 240246, 1967.

[9] M. Schönhuber, H. E. Urban, J. P. V. P. Baptista, W. L. Randeu, and W. Riedler, "Weather radar vs. 2D-video-distrometer data," in Weather Radar Technology for Water Resources Management, B. Braga Jr. and O. Massambani, Eds., UNESCO, New York, NY, USA, 1997.

[10] A. Tokay and D. A. Short, "Evidence from tropical raindrop spectra of the origin of rain from stratiform versus convective clouds," Journal of Applied Meteorology, vol. 35, no. 3, pp. 355371, 1996.

[11] T. Kozu and K. Nakamura, "Rainfall parameter estimation from dual radar measurements combining reflectivity profile and path-integrated attenuation," Journal of Atmospheric and Oceanic Technology, vol. 8, no. 2, pp. 259-271, 1991.

[12] J. T. Ong and Y. Y. Shan, "Modified gamma model for Singapore rain drop size distribution," in Proceedings of the IEEE International Geoscience and Remote Sensing Symposium (IGARSS '97), pp. 1757-1759, August 1997.

[13] G. Feingold and Z. Levin, "The lognormal fit to raindrop spectra from frontal convective clouds in Israel," Journal of Climate \& Applied Meteorology, vol. 25, no. 10, pp. 1346-1363, 1986.

[14] K. I. Timothy, J. T. Ong, and E. B. L. Choo, "Raindrop size distribution using method of moments for terrestrial and satellite communication applications in Singapore," IEEE Transactions on Antennas and Propagation, vol. 50, no. 10, pp. 1420-1424, 2002.

[15] C. W. Ulbrich and D. Atlas, "Rainfall microphysics and radar properties: analysis methods for drop size spectra," Journal of Applied Meteorology, vol. 37, no. 9, pp. 912-923, 1998.

[16] C. Caracciolo, F. Prodi, A. Battaglia, and F. Porcu', 'Analysis of the moments and parameters of a gamma DSD to infer precipitation properties: a convective stratiform discrimination algorithm," Atmospheric Research, vol. 80, no. 2-3, pp. 165-186, 2006.

[17] P. L. Smith and D. V. Kliche, "The bias in moment estimators for parameters of drop size distribution functions: Sampling from exponential distributions," Journal of Applied Meteorology, vol. 44, no. 8, pp. 1195-1205, 2005.

[18] A. Seifert, "On the shape-slope relation of drop size distributions in convective rain," Journal of Applied Meteorology, vol. 44, no. 7, pp. 1146-1151, 2005.

[19] Y. H. Chu and C. L. Su, "An investigation of the slopeshape relation for gamma raindrop size distribution," Journal of Applied Meteorology and Climatology, vol. 47, no. 10, pp. 25312544, 2008.

[20] P. T. Willis, "Functional fits to some observed drop size distributions and parameterization of rain," Journal of the Atmospheric Sciences, vol. 41, no. 9, pp. 1648-1661, 1984.

[21] J. Testud, S. Oury, R. A. Black, P. Amayenc, and X. Dou, "The concept of "normalized" distribution to describe raindrop spectra: a tool for cloud physics and cloud remote sensing," Journal of Applied Meteorology, vol. 40, no. 6, pp. 1118-1140, 2001.
[22] A. J. Illingworth and T. M. Blackman, "The need to represent raindrop size spectra as normalized gamma distributions for the interpretation of polarization radar observations," Journal of Applied Meteorology, vol. 41, no. 3, pp. 286-297, 2002.

[23] H. Sauvageot and J.-P. Lacaux, "The shape of averaged drop size distributions," Journal of the Atmospheric Sciences, vol. 52, no. 8, pp. 1070-1083, 1995.

[24] V. N. Bringi, V. Chandrasekar, J. Hubbert, E. Gorgucci, W. L. Randeu, and M. Schoenhuber, "Raindrop size distribution in different climatic regimes from disdrometer and dual-polarized radar analysis," Journal of the Atmospheric Sciences, vol. 60, no. 2, pp. 354-365, 2003.

[25] T. Islam, M. A. Rico-Ramirez, M. Thurai, and D. Han, "Characteristics of raindrop spectra as normalized gamma distribution from a Joss-Waldvogel disdrometer," Atmospheric Research, vol. 108, pp. 57-73, 2012.

[26] M. Montopoli, F. S. Marzano, and G. Vulpiani, "Analysis and synthesis of raindrop size distribution time series from disdrometer data," IEEE Transactions on Geoscience and Remote Sensing, vol. 46, no. 2, pp. 466-478, 2008.

[27] C. W. Ulbrich and D. Atlas, "Microphysics of raindrop size spectra: tropical continental and maritime storms," Journal of Applied Meteorology and Climatology, vol. 46, no. 11, pp. 17771791, 2007.

[28] R. S. Tenório, M. C. D. S. Moraes, and H. Sauvageot, "Raindrop size distribution and radar parameters in coastal tropical rain systems of northeastern Brazil," Journal of Applied Meteorology and Climatology, vol. 51, no. 11, pp. 1960-1970, 2012.

[29] T. Kozu, K. K. Reddy, S. Mori et al., "Seasonal and diurnal variations of raindrop size distribution in Asian monsoon region," Journal of the Meteorological Society of Japan, vol. 84, pp. 195-209, 2006.

[30] S. Moumouni, M. Gosset, and E. Houngninou, "Main features of rain drop size distributions observed in Benin, West Africa, with optical disdrometers," Geophysical Research Letters, vol. 35, no. 23, Article ID L23807, 2008.

[31] K. Krishna Reddy and T. Kozu, "Measurements of raindrop size distribution over Gadanki during south-west and north-east monsoon," Indian Journal of Radio and Space Physics, vol. 32, no. 5, pp. 286-295, 2003.

[32] I. Zawadzki and M. De Agostinho Antonio, "Equilibrium raindrop size distributions in tropical rain," Journal of the Atmospheric Sciences, vol. 45, no. 22, pp. 3452-3459, 1988.

[33] L. S. Kumar, Y. H. Lee, and J. T. Ong, "Two-parameter gamma drop size distribution models for singapore," IEEE Transactions on Geoscience and Remote Sensing, vol. 49, no. 9, pp. 3371-3380, 2011.

[34] T. Kozu, T. Shimomai, Z. Akramin, Y. Shibagaki, and H. Hashiguchi, "Intraseasonal variation of raindrop size distribution at Koto Tabang, West Sumatra, Indonesia," Geophysical Research Letters, vol. 32, no. 7, pp. 1-4, 2005.

[35] O. J. Bee and C. L. Sien, The Climate of West Malaysia and Singapore, Oxford University Press, London, UK, 1974.

[36] Distrometer RD-69 Instruction Manual, Distromet Ltd, 1993.

[37] R. Gunn and G. D. Kinzer, "The terminal velocity of fall for water droplets in stagnant air," Journal of the Atmospheric Science, vol. 6, no. 4, pp. 243-248, 1949.

[38] B. E. Sheppard and P. I. Joe, "Comparison of raindrop size distribution measurements by a Joss- Waldvogel disdrometer, a PMS 2DG spectrometer, and a POSS doppler radar," Journal of Atmospheric \& Oceanic Technology, vol. 11, no. 4, pp. 874-887, 1994. 
[39] T. Kozu, Estimation of raindrop size distribution from spaceborne radar measurement [Ph.D. thesis], Kyoto University, Kyoto, Japan, 1991.

[40] M. Montopoli, F. S. Marzano, G. Vulpiani, M. N. Anagnostou, and E. N. Anagnostou, "Statistical characterization and modeling of raindrop spectra time series for different climatological regions," IEEE Transactions on Geoscience and Remote Sensing, vol. 46, no. 10, pp. 2778-2787, 2008.

[41] W. L. Randeu, T. Kozu, T. Shimomai, H. Hashiguchi, and M. Schönhuber, "Raindrop axis ratios, fall velocities and size distribution over Sumatra from 2D-Video disdrometer measurement," Atmospheric Research, vol. 119, pp. 23-37, 2013.

[42] F. J. Tapiador, F. J. Turk, W. Petersen et al., "Global precipitation measurement: methods, datasets and applications," Atmospheric Research, vol. 104-105, pp. 70-97, 2012.

[43] A. Tokay, R. J. Roche, and P. G. Bashor, "An experimental study of spatial variability of rainfall," Journal of Hydrometeorology, vol. 15, no. 2, pp. 801-812, 2014.

[44] F. J. Tapiador, R. Checa, and M. de Castro, "An experiment to measure the spatial variability of rain drop size distribution using sixteen laser disdrometers," Geophysical Research Letters, vol. 37, no. 16, Article ID L16803, 2010.

[45] A. Berne and R. Uijlenhoet, "Path-averaged rainfall estimation using microwave links: uncertainty due to spatial rainfall variability," Geophysical Research Letters, vol. 34, no. 7, Article ID L07403, 2007.

[46] E. F. Wood, M. Sivapalan, K. Beven, and L. Band, "Effects of spatial variability and scale with implications to hydrologic modeling," Journal of Hydrology, vol. 102, no. 1-4, pp. 29-47, 1988.

[47] E. Adirosi, E. Gorgucci, L. Baldini, and A. Tokay, "Evaluation of gamma raindrop size distribution assumption through comparison of rain rates of measured and radar-equivalent gamma DSD," Journal of Applied Meteorology and Climatology, vol. 53, pp. 1618-1635, 2014.

[48] M. Le and V. Chandrasekar, "An algorithm for drop-size distribution retrieval from GPM dual-frequency precipitation radar," IEEE Transactions on Geoscience and Remote Sensing, vol. 52, no. 11, pp. 7170-7185, 2014.

[49] F. J. Tapiador, Z. S. Haddad, and J. Turk, "A probabilistic view on raindrop size distribution modeling: a physical interpretation of rain microphysics," Journal of Hydrometeorology, vol. 15, no. 1, pp. 427-443, 2014. 

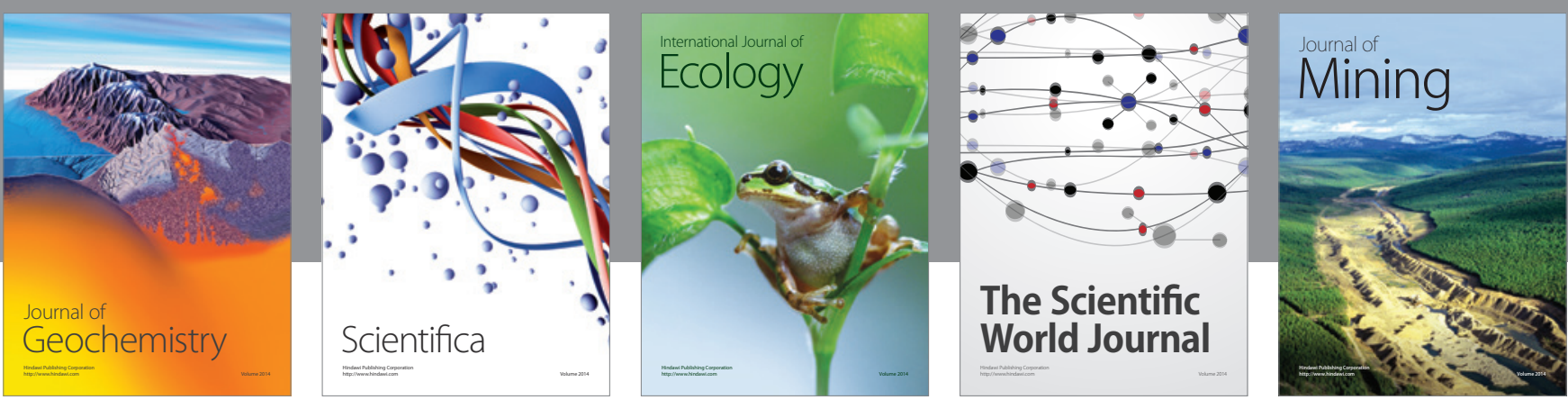

The Scientific World Journal
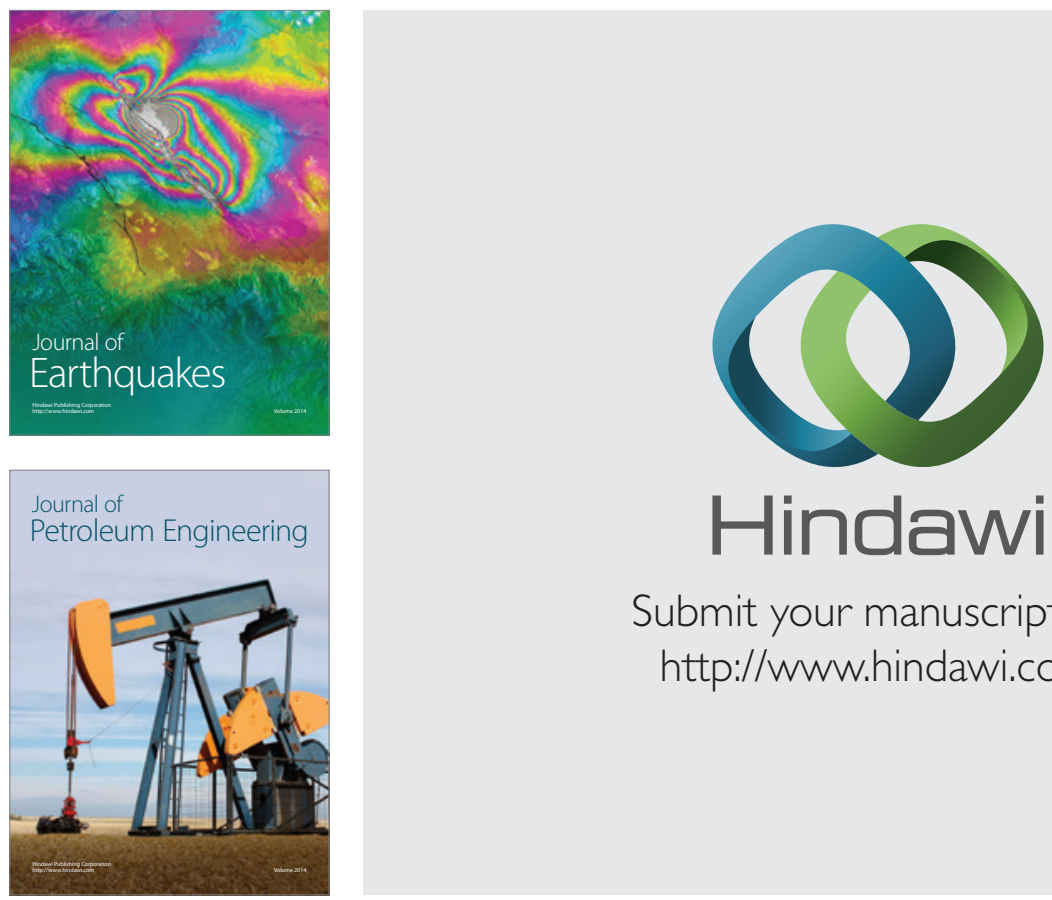

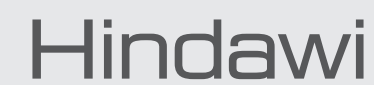

Submit your manuscripts at

http://www.hindawi.com
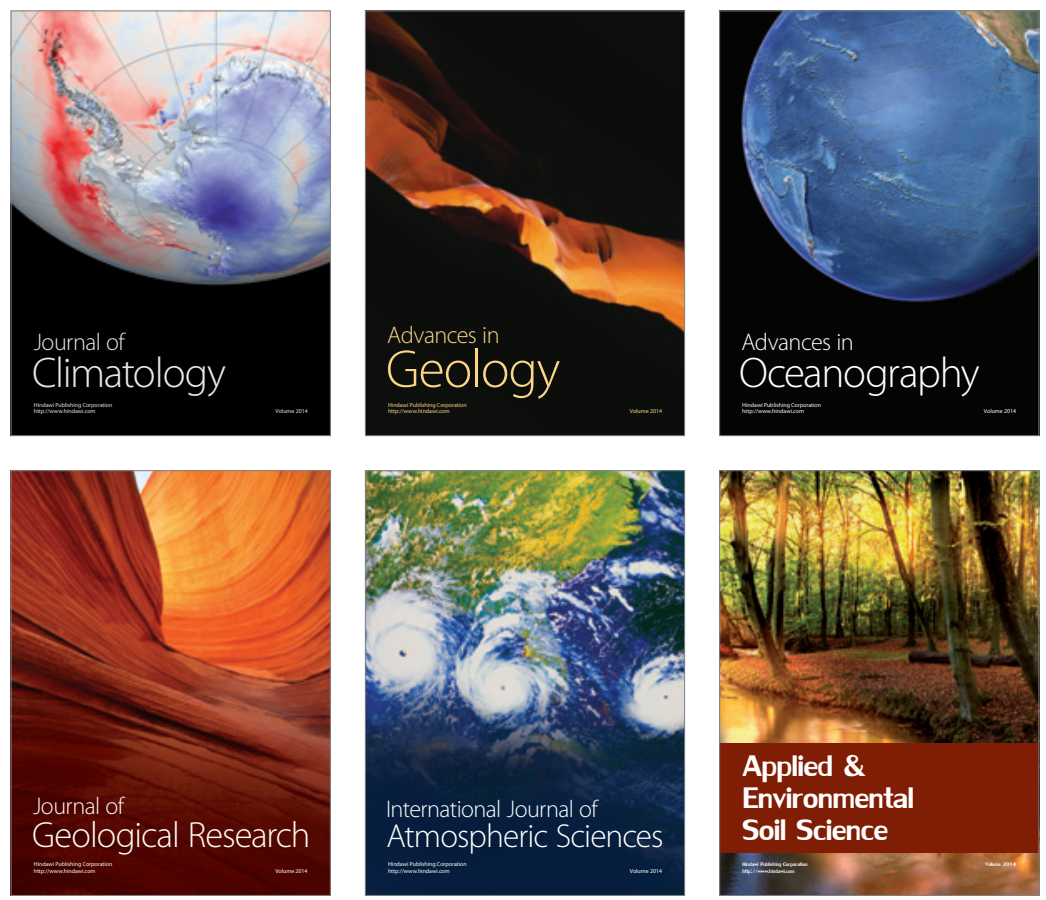
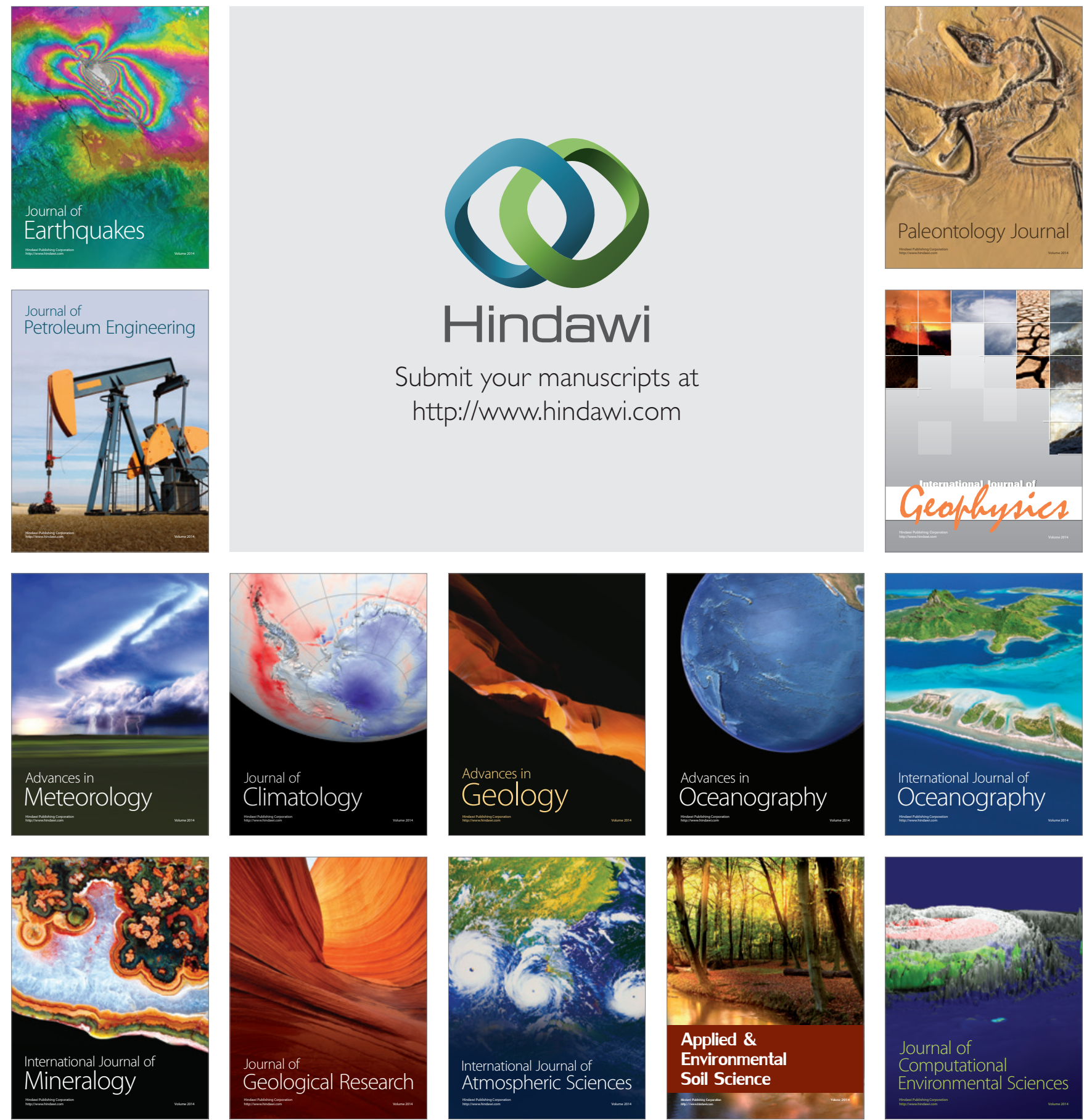